\title{
O USO VARIÁVEL DA CONCORDÂNCIA SOB A ÓTICA DE PROFESSORES DE LÍNGUA PORTUGUESA E MATEMÁTICA
}

\author{
Marília Silva Vieira (UEG) \\ Rodrigo Borges Gonçalves (UEG)
}

Resumo: A língua se revela heterogênea, influenciada não apenas por forças internas, mas também por pressões externas. Logo, quando um falante qualquer se expressa por meio da língua, ele não transmite apenas os sentidos produzidos pelos signos linguísticos, mas também significados sociais compartilhados pela comunidade. Para aferir as crenças e atitudes de professores graduados em Letras e em Matemática de Quirinópolis, no sudoeste goiano, em relação às variações em concordância verbal e concordância nominal, esta pesquisa lançou mão de uma técnica de medição indireta chamada matched guise. Nesse sentido, as ações realizadas neste estudo basearam-se nos preceitos da Sociolinguística (LABOV, 2008; 2001; 1994; 1966; ECKERT, 2012; BOTASSINI, 2013) e na Sociolinguística Educacional (BORTONI-RICARDO, 2004). Os resultados apontados pela investigação da variação nas comunidades de práticas em questão evidenciaram que os professores de Matemática apresentaram rejeição mais saliente às variáveis pesquisadas, comparativamente aos professores de Língua Portuguesa. Logo, reforça-se a necessidade de que o ensino de Língua Portuguesa seja embasado em preceitos da variação linguística, inclusive na formação dos docentes de fora da área de Letras.

Palavras-chave: Crenças; Atitudes; Sudoeste Goiano; Ensino.

Abstract: The language proves to be heterogeneous, influenced not only by internal forces, but also by external pressures. Therefore, when any speaker expresses himself through the language, he not only conveys the meanings produced by linguistic signs, but also social meanings shared by the community. To determine how beliefs and attitudes of teachers who are graduated in Languages and Mathematics from Quirinópolis, in the southwest of Goiás, in relation to variations of verbal and nominal agreement, this work applied an indirect use technique called Matched Guise. In this sense, the actions carried out in this study were based on the precepts of Sociolinguistics (LABOV, 2008; 2008; 2001; 1994; 1966; 
Eckert, 2012; BOTASSINI, 2013) and on the Educational Sociolinguistics (BORTONI-RICARDO, 2004). The results pointed out by the investigation of variation in the communities of practice in question showed that mathematics teachers rejected the researched variables much more than Portuguese language teachers. Therefore, this search discusses the inclusion of sociolinguistic precepts in the training of teachers outside the area of Languages.

Keywords: Beliefs; Attitudes; Southwest of Goiás; Teaching.

\section{INTRODUÇÃO}

A sociedade contemporânea é marcada pela heterogeneidade social, cultural, política e econômica. Estar imerso nesse contexto diversificado requer conhecimentos e habilidades para lidar com as contradições deflagradas pelo choque das diferentes formas de ser/estar no mundo. O homem é um ser social, logo, a linguagem também é social. A língua, por se desenvolver nesse ambiente variado, também se revela heterogênea, influenciada não apenas por forças internas, mas também por pressões externas. Consequentemente, quando um falante qualquer se expressa por meio da língua, ele não transmite apenas os sentidos produzidos pelos signos linguísticos, mas também revela significados sociais, relacionados à origem geográfica, à faixa etária, ao sexo/gênero, ao nível de escolaridade e à sua identificação com comunidades de práticas específicas.

As diferentes variedades linguísticas podem estar relacionadas às camadas que gozam de prestígio ou não, 
fator que atua no desdobramento de crenças e atitudes linguísticas, que revestem de poder algumas manifestações linguísticas e rechaçam outras. Assim o preconceito linguístico se ergue no seio social, por meio da polarização do "certo" e do "errado" na língua. Para superar essa dicotomia, é necessário educar e conscientizar os alunos, valorizando as diferenças linguísticas de cada um.

Nesse sentido, é imprescindível que a escola prepare o indivíduo para interagir de forma consciente e responsável em seu convívio social. Uma das principais bagagens que o aluno leva para a escola é sua linguagem e como o contexto escolar também é marcado pela pluralidade social, cultural e econômica, a variedade de alguns estudantes pode ser estigmatizada. A fim de se alcançar uma educação mais inclusiva e não excludente, é essencial que o professor tenha consciência do valor do conhecimento que o aluno traz de casa, principalmente de sua variedade linguística.

Entende-se, então, que o aluno não deve ser apenas receptor de conteúdo, objeto de ensino; mas sim, sujeito, produtor de conhecimento e, em se tratando do processo de ensino-aprendizagem de língua materna, é mister o reconhecimento e a valorização das diversas formas de se expressar, pois todas são formas legítimas. Ao tratar da 
competência do professor no que tange à legitimação do conhecimento prévio do aluno, Demo (2015) defende que:

A base cultural própria é o ponto de partida e referência constante, não o limite do desenvolvimento. A cultura não é só memória e preservação. É também o chão do futuro feito com propriedade. Por isso, aproveitar o que o aluno já sabe, acumulou de experiência pessoal, apresenta como identidade cultural é habilidade crucial do professor, por conta da relação de sujeito. (p.32)

Ao considerar a relevância social de tornar o processo de ensino-aprendizagem cada vez mais profícuo e a necessidade de se formar professores munidos de consciência linguística, este trabalho discute sobre a relevância da inclusão do debate sociolinguístico nos cursos de formação de professores, de modo a evitar que o desenvolvimento de crenças e atitudes linguísticas negativas dos docentes possam inibir a performance dos discentes. Além disso, este estudo propõe a estimulação do ensino baseado na pesquisa, desde a Educação Básica, com o propósito de desenvolver a habilidade do indivíduo de produzir novos conhecimentos e evitar a reprodução passiva de conteúdos.

Embasada na teia teórica da Sociolinguística Variacionista (LABOV, 2008), esta pesquisa visa elucidar possíveis crenças e atitudes linguísticas de dois grupos de professores a respeito 
do uso variável da concordância nominal e da concordância verbal. Para isso, utilizou-se a técnica matched guise, ou falsos pares, que, segundo Labov (2008), foi desenvolvida por Lambert (1967) e é o instrumento básico para o estudo de reações subjetivas à linguagem.

O teste foi aplicado na cidade de Quirinópolis, situada no Sudoeste goiano, onde a expansão demográfica provocada pela instalação de duas usinas sucroalcooleiras na região desencadeou a imigração de trabalhadores de diversas regiões diferentes do país, ampliando e intensificando choques culturais no município.

Ao examinar as crenças e atitudes linguísticas dos professores de Língua Portuguesa e Matemática, mediante a análise de suas percepções em relação às variáveis em estudo, a saber, a concordância nominal e a concordância verbal, almeja-se trazer à tona reações negativas que materializem a necessidade do ensino de Língua Portuguesa à luz de preceitos sociolinguísticos (BORTONI-RICARDO, 2004), em cursos de formação de professores, e do fomento de pesquisas como prática pedagógica na Educação Básica. Desse modo, será possível produzir conhecimento a partir da própria língua, enquanto tomam consciência de questões histórico-sociais relacionadas a ela. 


\section{FUNDAMENTAÇÃO TEÓRICA}

A Sociolinguística explora a relação entre a língua que falamos e a sociedade em que vivemos, explorando a convergência de abordagens para uma descrição mais ampla e integrada dos fenômenos linguísticos no contexto social (FREITAG; CYRANKA, 2014). Nas palavras de Silva-Corvalán:

É uma disciplina independente, com metodologia própria, desenvolvida principalmente nos Estados Unidos e Canadá a partir dos anos sessenta, que estuda a língua em seu contexto social e se preocupa essencialmente em explicar a variação linguística, e sua relação com fatores sociais e do papel que esta variação desempenha nos processos de mudança linguística. ${ }^{1}$ (1989, p.1, tradução nossa)

Como o olhar deste estudo sociolinguístico se expande para o contexto escolar, faz-se necessário alicerçá-lo, também, nos preceitos da Sociolinguística Educacional (BORTONI-RICARDO, 2004), cujo objetivo é o direcionamento dos estudos sociolinguísticos para a formação de professores, contribuindo, simultaneamente, para o ensino de língua materna.

Acredita-se que, ao munir o professor com um instrumental sociolinguístico, ele pode desenvolver práticas

1 Es una disciplina independiente, con una metodología propia, desarrollada principalmente en los Estados Unidos y Canadá a partir de los años sesenta, que estudia la lengua en su contexto social, y se preocupa esencialmente de explicar la variabilidad lingüística, de su interrelación con factores sociales y del papel que esta variabilidad desempeña en los procesos de cambio linguístico. 
pedagógicas coerentes a fim de promover condições para que os alunos compreendam e assimilem o fenômeno da variação linguística, de modo que tomem consciência das crenças e atitudes linguísticas que desencadeiam o preconceito linguístico, tornando, assim, o ambiente escolar menos segregador e abrindo caminho para uma educação mais significativa para os envolvidos no processo de ensinoaprendizagem. Segundo Demo (2015):

A pesquisa inclui sempre a percepção emancipatória do sujeito que busca fazer e fazer-se oportunidade, à medida que começa e se reconstitui pelo questionamento sistemático da realidade. Incluindo a prática como componente necessário da teoria, e vice-versa, englobando a ética dos fins e valores. (p.9)

Para formar, o professor precisa, sobretudo, de embasamento científico e domínio conceitual sobre a linguagem em seu funcionamento social. Somente assim poderá superar reflexões superficiais, engendradas no senso comum e poderá, aos poucos, fazer da sala de aula um laboratório de linguagem, onde os alunos serão investigadores e agentes do processo de descrição linguística. Desse modo, o ensino da língua pode se tornar significativo e eficaz, de modo que o aluno compreenda como as relações de poder estão associadas à língua, produzindo diferentes significados sociais. 
Para finalizar o panorama da fundamentação teórica deste estudo, é relevante mencionar a técnica de medição indireta, que permite o desvelamento de crenças e atitudes linguísticas e que foi assim descrita por Labov (2008):

O princípio essencial que emerge do trabalho de Lambert é o de que existe um conjunto uniforme de atitudes frente à linguagem que são compartilhadas por quase todos os membros da comunidade de fala, seja no uso de uma forma estigmatizada ou prestigiada da língua em questão. Essas atitudes não emergem de forma sistemática se a pessoa for questionada diretamente sobre os dialetos; mas se ela fizer dois conjuntos de julgamentos de personalidade sobre o mesmo falante usando duas formas diferentes da língua, e se não perceber que é o mesmo falante, suas avaliações subjetivas da língua emergirão como diferenças nas duas pontuações. (p.176)

Nessa técnica, os informantes desempenham o papel de "juízes", ao emitir julgamentos positivos ou negativos acerca de determinado fenômeno de variação linguística, como o uso variável da concordância nominal e verbal. Para isso, são exibidos estímulos sonoros aos julgadores, que emitem seus pareceres a partir de uma escala de avaliação, baseada em critérios sociais.

\section{METODOLOGIA}

O caminho metodológico desta pesquisa se inicia pelos estudos da primeira onda da Sociolinguística. Segundo 
Eckert (2012), cada onda é entendida como tendências de estudos, que não se suplantam, nem são sucessivas cronologicamente, mas evidenciam a gradação entre o social e o linguístico. Os estudos dessa tendência enfatizam as comunidades de fala que, segundo Labov (2008, p.188), "não pode ser concebida como um grupo de falantes que usam todos as mesmas formas; ela é mais bem definida como um grupo que compartilha as mesmas normas a respeito da língua". Nesse sentido, o lócus de nossa pesquisa é a cidade de Quirinópolis, localizada no Sudoeste goiano, a cerca de 300 km da capital, Goiânia.

Para elaborar o teste aplicado aos juízes, recorreu-se a um corpus sociolinguístico composto de 16 entrevistas com falantes nativos de Quirinópolis, (os entrevistados compreendem 8 homens e 8 mulheres, estratificados em duas faixas etárias: 20-34 anos e 45 a 60 anos), do qual foram extraídos trechos caracterizados pela presença e pela ausência da concordância nominal e verbal.

Embora se utilize da metodologia da primeira onda para compor o corpus, o presente trabalho não se encaixa nessa tendência, por não se ater a explicações estatísticas, nem se dedicar à compreensão de uma variável em uma comunidade de fala. Justifica-se, pois, dados os objetivos da pesquisa, sua 
inclusão na teia teórico-metodológica da terceira onda da Sociolinguística, visto que seu foco são duas comunidades de práticas e as crenças e atitudes de cada uma delas acerca de duas variáveis linguísticas.

Por comunidade de práticas, compreendem-se as práticas sociais compartilhadas por indivíduos engajados em prol de uma meta comum e que envolvem desde crenças e valores até modos de praticar atividades específicas e de se expressar. A comunidade de práticas alvo deste estudo é representada por 5 professores graduados em Letras e 5 graduados em Matemática.

Quirinópolis é caracterizada por diferentes falares, oriundos da instalação de usinas sucroalcooleiras na cidade, o que desencadeou um processo imigratório que quase dobrou a população da cidade e que polarizou o local em dois grupos: os quirinopolinos e os "usineiros". Enquanto o primeiro termo é sinônimo de prestígio e pertencimento, o segundo é carregado de estigma e preconceito, pois denomina aquele que é visto como um invasor e que, frequentemente, é culpabilizado pelo aumento da violência na cidade.

Ao analisar o corpus de fala com informantes quirinopolinos, vários exemplos de uso variável de 
concordância verbal e nominal foram identificados e, a seguir, procedeu-se a escolha daqueles que comporiam o teste de percepção em que se baseia esta pesquisa. Para isso, levouse em consideração o seguinte questionamento: "Como os professores da cidade de Quirinópolis se comportam diante dos estilos de linguagem que compõem a fala local?" (aqui representados por duas variáveis, a concordância nominal e a concordância verbal).

Como objetiva-se argumentar a favor de uma formação docente em prol da consciência linguística, optou-se por dividir a amostra entre professores graduados em Letras e professores graduados em Matemática, pelo fato de os primeiros apresentarem uma formação com ênfase na linguagem, o que não caracteriza os membros do segundo grupo. Para responder à pergunta supramencionada e descrever as crenças e atitudes linguísticas relacionadas aos fenômenos em questão, cada juiz respondeu dois questionários, tais como os desenvolvidos por Botassini (2013) e Vieira (2019).

No primeiro questionário, os professores avaliaram o excerto (01) cuja informante é identificada no corpus como QNP24FSO (QNP: quirinopolina; 24: 24 anos; F: sexo/ gênero feminino; S: Ensino Superior). No segundo, o (02) cuja informante é identificada no corpus como QNP46FC 
(QNP: quirinopolina, 46: 46 anos; F: sexo/gênero feminino; C: colegial, ou seja, Ensino Médio).

(01) Nós foi no mesmo dia. Nós foi num dia e voltou logo após terminar a formatura.

(02) Eu acho que era diferente nas matéria. Eu acho que era mais fácil.

Para preservar a identidade dos participantes, primando pela ética na pesquisa, eles serão nomeados como $L 1, L 2, L 3$, L4, L5, M1, M2, M3, M4 e M5. Cada um recebeu uma cópia dos questionários por e-mail.

Respondente 1

Graduação em Letras

Nós foi no mesmo dia. Nós foi num dia e voltou logo após terminar a formatura.

A pessoa que está falando: Muito pouco

\begin{tabular}{|l|l|l|l|l|l|l|}
\hline parece inteligente & 1 & 2 & 3 & 4 & 5 & 6 \\
\hline parece amigável & 1 & 2 & 3 & 4 & 5 & 6 \\
\hline parece educada & 1 & 2 & 3 & 4 & 5 & 6 \\
\hline parece fisicamente atraente & 1 & 2 & 3 & 4 & 5 & 6 \\
\hline parece ter senso de humor & 1 & 2 & 3 & 4 & 5 & 6 \\
\hline parece confiável & 1 & 2 & 3 & 4 & 5 & 6 \\
\hline parece interessada em progredir & 1 & 2 & 3 & 4 & 5 & 6 \\
\hline parece ter mente aberta & 1 & 2 & 3 & 4 & 5 & 6 \\
\hline parece autoconfiante & 1 & 2 & 3 & 4 & 5 & 6 \\
\hline parece generosa & 1 & 2 & 3 & 4 & 5 & 6 \\
\hline parece capaz de ser líder & 1 & 2 & 3 & 4 & 5 & 6 \\
\hline parece ser engraçada & 1 & 2 & 3 & 4 & 5 & 6 \\
\hline parece ser orgulhosa & 1 & 2 & 3 & 4 & 5 & 6 \\
\hline parece ser fiel & 1 & 2 & 3 & 4 & 5 & 6 \\
\hline parece ser objetiva & 1 & 2 & 3 & 4 & 5 & 6 \\
\hline parece aceitar novos usos e costumes & 1 & 2 & 3 & 4 & 5 & 6 \\
\hline
\end{tabular}

Figura 1 - Teste da variável concordância verbal²

2 Fonte: Elaboração própria. 
Tanto no teste 1 , formulado a partir de um trecho marcado pela falta de concordância verbal, quanto no 2, em que o fenômeno principal é falta de concordância nominal, o juiz deveria avaliar o estímulo sonoro em uma escala de 1 a 6 , em que 1 simboliza a avaliação mais negativa possível em relação ao critério social considerado e 6, a mais positiva.

Cada questionário contém 16 afirmativas, apontando atributos que deveriam ser avaliados e que somam um total de 320 julgamentos $(10 \times 2=20 ; 20 \times 16=320)$. Todas as características que compõem o teste são positivas e dividem-se em competência (inteligente, capaz de ser líder, autoconfiante), integridade pessoal (educada, confiável, fiel) e atratividade social (amigável, fisicamente atraente, ter senso de humor, generosa). 
Respondente 1

Graduação em Letras

Eu acho que era diferente nas matéria. Eu acho que era mais fácil.

A pessoa que está falando: Mu ito pouco parece inteligente parece amigável parece educada parece fisicamente atraente parece ter senso de humor parece confiável parece interessada em progredir parece ter mente aberta parece autoconfiante parece generosa parece capaz de ser líder parece ser engraçada parece ser orgulhosa parece ser fiel parece ser objetiva parece aceitar novos usos e costumes

\begin{tabular}{|l|l|l|l|l|l|}
\hline 1 & 2 & 3 & 4 & 5 & 6 \\
\hline 1 & 2 & 3 & 4 & 5 & 6 \\
\hline 1 & 2 & 3 & 4 & 5 & 6 \\
\hline 1 & 2 & 3 & 4 & 5 & 6 \\
\hline 1 & 2 & 3 & 4 & 5 & 6 \\
\hline 1 & 2 & 3 & 4 & 5 & 6 \\
\hline 1 & 2 & 3 & 4 & 5 & 6 \\
\hline 1 & 2 & 3 & 4 & 5 & 6 \\
\hline 1 & 2 & 3 & 4 & 5 & 6 \\
\hline 1 & 2 & 3 & 4 & 5 & 6 \\
\hline 1 & 2 & 3 & 4 & 5 & 6 \\
\hline 1 & 2 & 3 & 4 & 5 & 6 \\
\hline 1 & 2 & 3 & 4 & 5 & 6 \\
\hline 1 & 2 & 3 & 4 & 5 & 6 \\
\hline 1 & 2 & 3 & 4 & 5 & 6 \\
\hline 1 & 2 & 3 & 4 & 5 & 6 \\
\hline
\end{tabular}

Figura 2 - Teste da variável concordância nominal ${ }^{3}$

Detectou-se, contudo, uma dificuldade quanto à escolha de um dos aspectos elencados para o teste. Segundo o dicionário Houaiss, o adjetivo orgulhosa, 13ํㅡ na sequência do teste, apresenta duas acepções: uma positiva, que descreve quem se envaidece por algo ou alguém, e outra negativa, que assinala arrogância. Por isso, optou-se por desconsiderar as respostas atribuídas a esse item, devido a um impasse no momento de definir se as avaliações eram positivas ou

3 Fonte: Elaboração própria. 
negativas. Reduziu-se, então, o quantitativo de avaliações, que totalizaram 300.

\section{RESULTADOS}

Para a análise dos resultados, foram consideradas positivas as respostas representadas pelos números 5 ou 6 que, gradativamente, correspondiam a "parece muito" e foram consideradas negativas as respostas representadas pelos números 1 ou 2 que, decrescentemente, correspondiam a "parece muito pouco". Por outro lado, foram consideradas neutras, as respostas representadas por 3 ou 4. Os gráficos a seguir demonstram como cada comunidade de práticas procedeu quanto à avaliação:

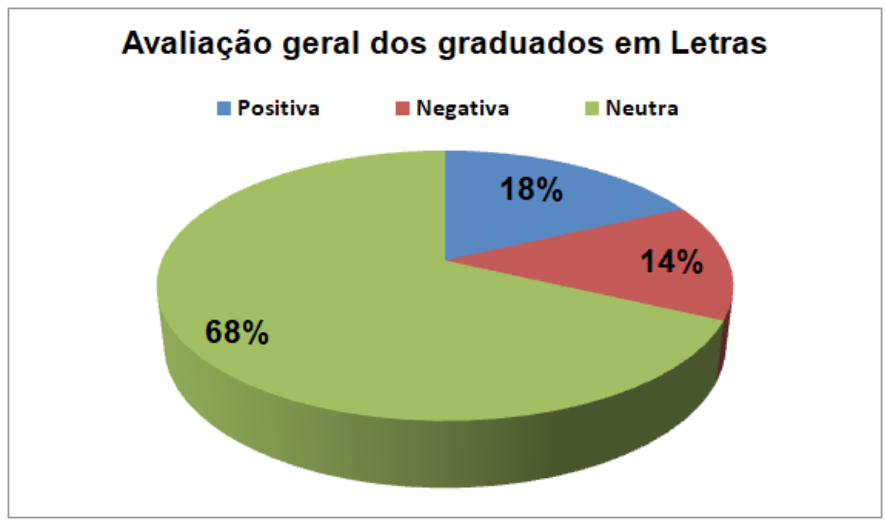

Gráfico 1 - Avaliação dos graduados em Letras ${ }^{4}$

4 Fonte: Elaboração própria. 


\section{Avaliação geral dos graduados em}

Matemática

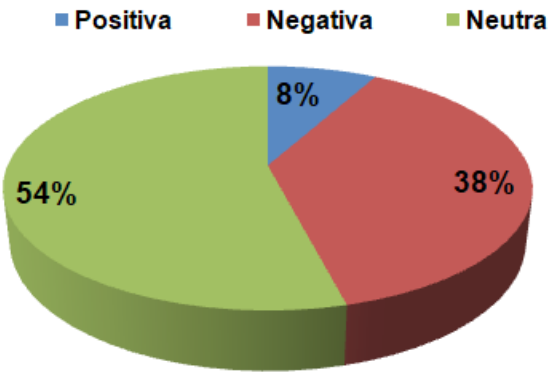

Gráfico 2 - Avaliação dos graduados em Matemática ${ }^{5}$

Somando-se os resultados dos testes 1 e 2, é possível observar que os dois grupos apresentaram números mais expressivos no que tange à avaliação neutra. Embora os graduados em Letras apresentem uma diferença de 14 pontos em relação aos matemáticos, nesse quesito, há semelhanças na origem das avaliações. Os matemáticos neutralizaram 31 vezes as avaliações referentes à integridade pessoal (educada, confiável, interessada em progredir, fiel e mente aberta) e 37 vezes aquelas que dizem respeito à atratividade social (amigável, fisicamente atraente, senso de humor, generosa e engraçada).

Os graduados em Letras, por sua vez, emitiram 38 avaliações neutras no que tange à integridade pessoal e 39 em relação às características de atratividade social.

5 Fonte: Elaboração própria. 
Portanto, pode-se inferir que há uma tendência de ambas as comunidades de práticas em neutralizar as avaliações dessas duas categorias, evidenciando certa dificuldade em se posicionar com relação a esses atributos.

Áreas de avaliação

Integridade pessoal

Atratividade social

Competência
Graduados em Letras

38

39

37

25
Graduados em

Matemática

Tabela 1 - Avaliação neutra ${ }^{6}$

De modo geral, 78 avaliações negativas foram emitidas, o que corresponde a $26 \%$ das avaliações. Por outro lado, 183 avaliações são neutras, isto é, 61\%; e apenas 39 foram positivas, o que caracteriza $13 \%$ das 300 avaliações. Observase que os professores de Língua Portuguesa emitiram 27 das 39 avaliações positivas, perfazendo 69,24\% do total, enquanto os docentes de Matemática emitiram apenas 12 de avaliações positivas, o que corresponde a 30,76\%.

Esses percentuais evidenciam que os professores formados em Letras tendem a emitir mais avaliações positivas, porém, mais uma vez, os números foram bem semelhantes

6 Fonte: Dados da pesquisa. 
quando se comparam os quesitos que envolvem integridade pessoal e atratividade social. Tal resultado é oriundo das qualidades relacionadas à competência (inteligente, objetiva, autoconfiante, capaz de ser líder e aceita novos costumes). Tais informações ficam mais claras na tabela 2:

\section{Áreas de avaliação}

Graduados em Letras

Graduados em

Matemática

Integridade pessoal

Atratividade social

Ainda considerando as avaliações positivas, com relação ao grupo da Matemática, apenas um juiz é responsável por 9 de 12 avaliações. M4 emitiu sozinho 75\% das avaliações positivas dessa comunidade de práticas, ao passo que as outras 3 avaliações foram emitidas por M2. Portanto, dos 5 juízes de Matemática, apenas 2 emitiram avaliações positivas e todos os demais emitiram avaliações negativas ${ }^{8}$.

Quando se observam apenas as avaliações negativas, o grupo de Matemática discordou 57 vezes, enquanto o grupo de Letras emitiu apenas 21 avaliações negativas de 300

7 Fonte: Dados da pesquisa.

8 A avaliação individual dos "juízes" pode ser conferida nas tabelas 8 e 9. 
possíveis, ou seja, $19 \%$ de todas as avaliações feitas pelos professores de Matemática foram negativas, enquanto somente $7 \%$ de todas as avaliações do grupo de Letras demonstraram discordância.

Sobre as avaliações negativas do grupo de Letras, apenas duas características se destacaram negativamente: 5 avaliações de 10 possíveis, apontam que a pessoa não parece ser objetiva e 3 avaliações de 10 possíveis, mostram que a pessoa não parece ser autoconfiante.

\section{Áreas de avaliação \\ Graduados em Letras \\ Graduados em Matemática}

Integridade pessoal

4

Atratividade social

4

8

Competência

13

Tabela 3 - Avaliação negativa9

As respostas negativas mais recorrentes dos professores de Matemática apontam que as pessoas que não utilizam a concordância nominal e verbal não parecem inteligentes, não parecem capazes de ser líderes, não parecem interessadas em progredir e não parecem ser autoconfiantes. Essas avaliações evidenciam que a imagem social construída pelo

9 Fonte: Dados da pesquisa. 
grupo em relação às variações linguísticas é marcada por desprestígio social. Ao considerar as avaliações de ambas as comunidades de práticas com relação aos estímulos apresentados, o estudo revelou os seguintes resultados para a concordância verbal:

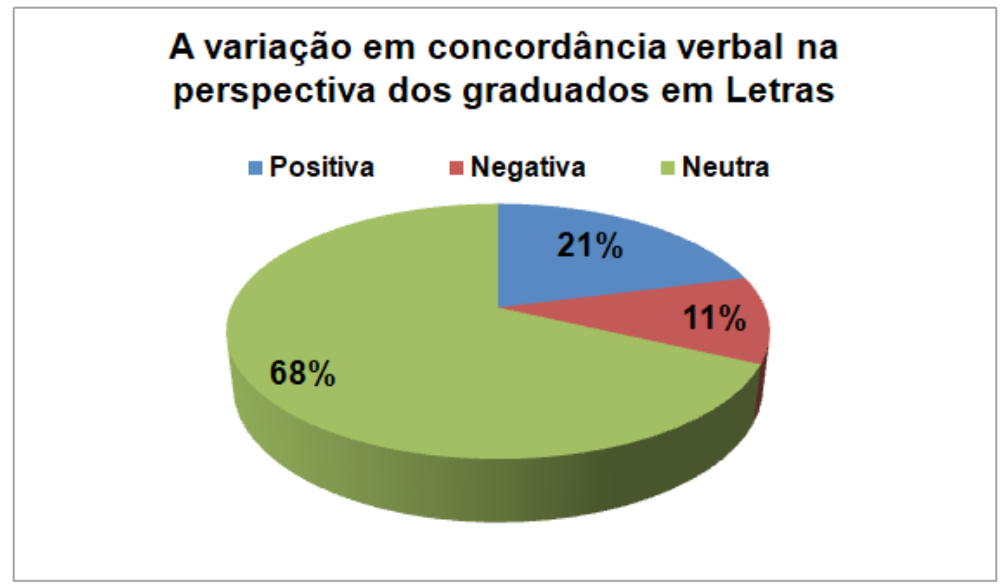

Gráfico 3 - A variação em concordância verbal: graduados em Letras ${ }^{10}$

Os professores graduados em Letras emitiram um número significativamente menor de atitudes negativas que os docentes de Matemática, uma vez que apenas uma alternativa foi avaliada negativamente pela maioria dos "juízes". Três avaliações indicam que os informantes (cujas vozes são exibidas nos estímulos) não parecem ser objetivos e dois julgaram que eles não parecem capazes de liderar.

10 Fonte: Dados da pesquisa. 


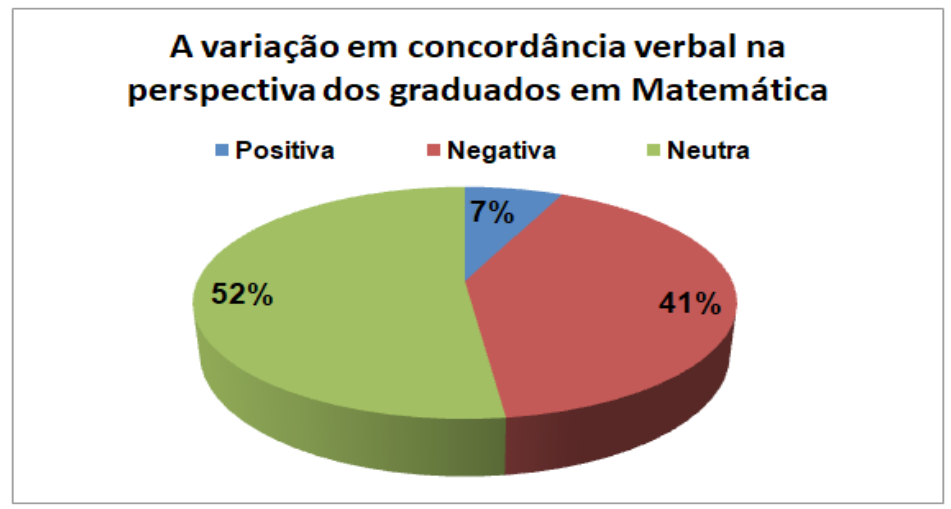

Gráfico 4 - A variação em concordância verbal: graduados em Matemática ${ }^{11}$

Com relação às atitudes negativas do grupo da Matemática, as 31 avaliações estão distribuídas como indicado na tabela 4.

\section{A pessoa que fala}

Parece ser capaz de ser líder

Parece ser objetiva

Parece inteligente

Parece interessada em progredir

Parece ser mente aberta

Parece ser autoconfiante

Parece aceitar novos usos e costumes

Parece fisicamente atraente

Parece ter senso de humor

Parece ser engraçada

\section{Número de avaliações}

5

4

4

3

3

3

2

1

1

Tabela 4 - Avaliações negativas do grupo de Matemática em relação à concordância verbal ${ }^{12}$

11 Fonte: Dados da pesquisa.

12 Fonte: Dados da pesquisa. 
Os cinco "juízes" de Matemática foram unânimes em afirmar que as informantes não pareciam capazes de exercer cargo de liderança e também não pareciam objetivos. Quatro avaliaram que as pessoas não pareciam inteligentes e nem interessadas em progredir. Três julgaram que as pessoas não pareciam ter mente aberta, não pareciam ser autoconfiantes, nem pareciam aceitar novos usos e costumes e dois afirmam que as pessoas não pareciam atraentes. Tais crenças evidenciam certo grau de desaprovação social, logo, falantes que não empregam a concordância verbal podem ter sua fala estigmatizada. Ao considerar as avaliações de cada grupo relacionadas aos fenômenos de variação isolados, o estudo revelou os seguintes resultados para a concordância nominal.

Um fato curioso foi constatado, ao verificar que para os olhos dos graduados em Letras, a concordância nominal apresentou um número maior de reprovação, isso é surpreendente porque, geralmente, problemas de concordância verbal são mais perceptíveis e salientes. Diferentemente, o grupo da Matemática seguiu a tendência ao emitir maior reprovação para a variação em concordância verbal. Mais uma vez, o número de avaliações negativas do grupo dos matemáticos foi superior ao dos graduados em Letras. As avaliações negativas da Matemática representam o dobro das emitidas pelo grupo de Letras. 


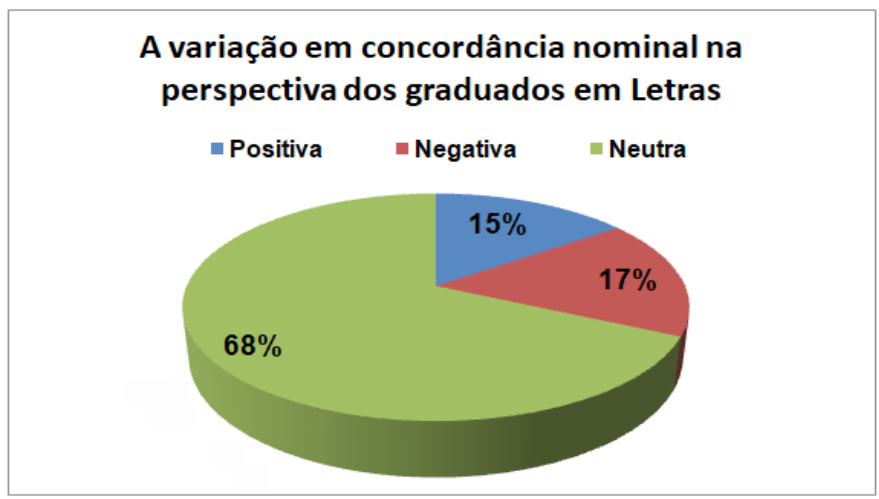

Gráfico 5 - A variação em concordância nominal: graduados em Letras ${ }^{13}$

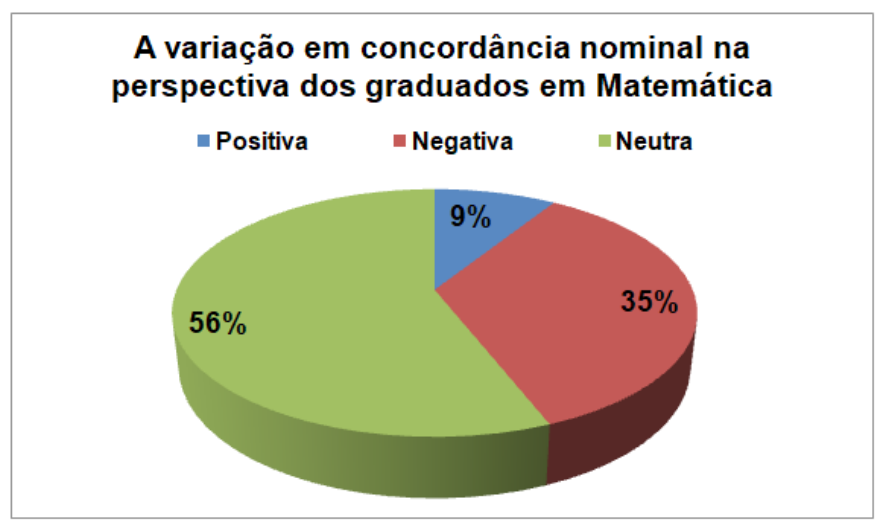

Gráfico 6-A variação em concordância nominal: graduados em Matemática ${ }^{14}$

Novamente, apenas uma alternativa foi avaliada negativamente pela maioria dos "juízes" de Letras, pois, para três deles, as pessoas que falavam não pareciam ser autoconfiantes. Dois julgaram que as pessoas não pareciam ser capazes de ser líder, dois avaliaram que as pessoas pareciam não ser confiáveis e, para dois, as pessoas não 13 Fonte: Dados da pesquisa.

14 Fonte: Dados da pesquisa. 
pareciam ser objetivas. É preciso ressaltar que 2 juízes são responsáveis por $77 \%$ das avaliações negativas do grupo, o que pode evidenciar que eles não tiveram contato com uma formação sociolinguística.

A tabela 5 descreve as 13 avaliações negativas dos graduados em Letras, que totalizam 75, 17\%. Apesar de caracterizar um percentual baixo, é notório que os professores graduados em Letras não estão isentos de atitudes negativas. Também não se pode afirmar que todos tiveram contato com a Sociolinguística em sua graduação, uma vez que, entre os juízes, há professores em início de carreira e outros mais experientes.

A pessoa que fala

Parece ser autoconfiante

Parece ser confiável

Parece capaz de ser líder

Parece ser objetiva

Parece ser engraçada

Parece ter senso de humor

Parece interessada a progredir

Parece fisicamente atraente

Número de avaliações

15 Fontes: Dados da pesquisa. 
Apenas quatro critérios foram avaliados positivamente por dois dos juízes, como pode ser visto na tabela 6 .

\section{A pessoa que fala}

Parece ser inteligente

Parece ser educada

Parece ser amigável

Parece ser objetiva

Parece ser mente aberta

Parece ser generosa

Parece aceitar novos usos e costumes
Número de avaliações

2

2

2

2

1

1

1

Tabela 6 - Avaliações positivas dos professores de Letras quanto à concordância nominal ${ }^{16}$

Percebe-se que os "juízes" de Matemática foram unânimes ao afirmar que o falante não parece inteligente, demonstrando crenças e atitudes negativas acerca da não concordância verbal. De acordo com quatro "juízes", o falante não parece capaz de ser líder e nem parece ser autoconfiante e, segundo três matemáticos, o falante também não parece interessado em progredir, como demonstra a tabela 7:

16 Fontes: Dados da pesquisa. 
Parece ser inteligente 5

Parece ser capaz de ser líder 4

Parece ser autoconfiante 4

Parece ser interessada em progredir

Parece ser mente aberta

Parece ser fisicamente atraente

Parece ser objetiva

Parece ter senso de humor

Parece ser engraçada

Parece ser confiável

Parece aceitar novos usos e costumes

Tabela 7-Avaliações negativas dos professores de Matemática quanto à concordância nominal ${ }^{17}$

Nota-se que apenas um “juiz", o M4 foi responsável por sete avaliações positivas, como se pode verificar na tabela 8. Logo, para quatro dos cinco professores, o não uso de concordância nominal, parece comprometer as qualidades dos falantes do teste.

17 Fontes: Dados da pesquisa. 


\section{Avaliações individuais dos graduados em Matemática}

\section{Critérios}

Parece inteligente

Parece amigável Concordância nominal Concordância verbal

Parece educada

Parece fisicamente atraente

Parece ter senso de humor

Parece confiável

Parece interessada em progredir

Parecer ter mente aberta

Parece autoconfiante

Parece generosa

Parece capaz de ser líder

Parece ser engraçada

Parece ser fiel

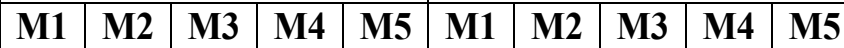

Parece ser objetiva

Parece aceitar novos usos e costumes 


\begin{tabular}{|c|c|c|c|c|c|c|c|c|c|c|}
\hline \multicolumn{11}{|c|}{ Avaliações individuais dos graduados em Letras } \\
\hline \multirow[t]{2}{*}{ Critérios } & \multicolumn{5}{|c|}{ Concordância Nominal } & \multicolumn{5}{|c|}{ Concordância Verbal } \\
\hline & L1 & $\mathbf{L 2}$ & L3 & L4 & L5 & L1 & L2 & L3 & L4 & L5 \\
\hline Parece inteligente & 4 & 5 & 3 & 5 & 4 & 5 & 4 & 3 & 5 & 4 \\
\hline Parece amigável & 5 & 5 & 4 & 4 & 3 & 5 & 5 & 4 & 5 & 3 \\
\hline Parece educada & 4 & 5 & 4 & 4 & 5 & 5 & 5 & 3 & 5 & 4 \\
\hline Parece fisicamente atraente & 3 & 4 & 3 & 1 & 3 & 3 & 4 & 3 & 1 & 3 \\
\hline Parece ter senso de humor & 3 & 4 & 3 & 1 & 3 & 3 & 4 & 3 & 3 & 3 \\
\hline Parece confiável & 4 & 2 & 3 & 1 & 3 & 6 & 4 & 4 & 4 & 4 \\
\hline Parece interessada em progredir & 3 & 4 & 3 & 2 & 4 & 4 & 4 & 4 & 5 & 4 \\
\hline Parecer ter mente aberta & 3 & 4 & 3 & 3 & 5 & 3 & 4 & 3 & 3 & 4 \\
\hline Parece autoconfiante & 2 & 2 & 2 & 3 & 4 & 4 & 5 & 4 & 3 & 3 \\
\hline Parece generosa & 5 & 4 & 4 & 3 & 3 & 3 & 4 & 4 & 4 & 4 \\
\hline Parece capaz de ser líder & 3 & 2 & 3 & 1 & 4 & 5 & 4 & 3 & 1 & 1 \\
\hline Parece ser engraçada & 3 & 4 & 3 & 1 & 4 & 3 & 5 & 3 & 3 & 3 \\
\hline Parece ser fiel & 3 & 4 & 4 & 3 & 3 & 3 & 4 & 4 & 1 & 3 \\
\hline Parece ser objetiva & 6 & 2 & 2 & 5 & 4 & 2 & 2 & 2 & 6 & 5 \\
\hline Parece aceitar novos usos e costumes & 4 & 4 & 3 & 4 & 5 & 3 & 4 & 3 & 5 & 2 \\
\hline
\end{tabular}

Tabela 9 - Avaliação individual dos professores de Letras19

As tabelas acima apresentam o desempenho individual dos juízes, demonstrando como a atuação dos 5 professores de cada comunidade de práticas contribuiu para os resultados gerais no que tange às crenças e atitudes acerca da concordância nominal e verbal.

\section{CONSIDERAÇÕES FINAIS}

Os resultados obtidos das análises dos questionários revelaram informações relevantes sobre as crenças e

19 Fonte: Dados da pesquisa. 
as atitudes dos professores graduados em Letras e em Matemática em relação às variáveis investigadas.

O alto índice de avaliações neutras demonstra que os dois grupos se mostraram indecisos, principalmente nos quesitos referentes à integridade pessoal e à atratividade social. Tal fato se deve, provavelmente, à dificuldade de avaliar uma pessoa apenas por características da sua fala, já que é possível encontrar pessoas com baixo nível de escolaridade e bem-sucedidas; por outro lado, também há pessoas com ensino superior, mas que não alcançaram a ascensão social. Sabe-se que a delimitação de classe social no Brasil não é muito precisa.

Com relação à variação em concordância verbal, as crenças e atitudes dos professores de Matemática evidenciam que o fenômeno em questão é estigmatizado, pois os docentes foram unânimes em afirmar que o falante não parece ser capaz de ser líder e não é objetivo. A maioria ainda apontou que a pessoa não parecia ser inteligente, autoconfiante e nem interessada em progredir. Essas pistas podem justificar a necessidade de inclusão da Sociolinguística na formação de docentes de modo geral, e não só no curso de Letras.

As crenças e atitudes dos professores de Matemática acerca do uso variável da concordância nominal também 
evidenciaram que tal fenômeno é estigmatizado por essa comunidade de práticas, pois os "juízes" foram unânimes em afirmar que a pessoa não parecia ser inteligente. Além disso, a maioria acredita que o falante não parecia capaz de ser líder, nem demonstrava ser autoconfiante e interessado em progredir. Nesse sentido, a inserção de uma perspectiva variacionista na formação dos docentes de Matemática pode contribuir significativamente para a conscientização em relação da heterogeneidade ordenada da língua.

As atitudes negativas dos graduados em Letras foram bem expressivamente menores. Com relação à variação em concordância verbal, apenas uma das características recebeu avaliação negativas, visto que 3 docentes apontaram que a pessoa não parecia ser objetiva. Com relação à variação da concordância nominal, apenas uma das alternativas foi avaliada negativamente pela maioria dos "juízes" de Letras. Três deles sinalizaram que o falante não parecia autoconfiante. Uma das prováveis hipóteses para tal resultado é o fato de que nem todos os docentes de Letras possam ter tido contato com a Sociolinguística na graduação.

Observa-se, então, como professores de diferentes comunidades de práticas reagem a crenças cristalizadas em relação à língua. Crenças linguísticas positivas e negativas 
podem se refletir na prática pedagógica, considerando-se que a sala de aula é um espaço onde habita a pluralidade linguística. Logo, a Sociolinguística cumpre um papel social importante, atuando na compreensão do significado social das diferentes manifestações da língua.

\section{REFERÊNCIAS}

BOTASSINI, J. O. M (2013). "Avaliação dialetal por meio de medição indireta". Revista Línguas \& Letras - Unioeste - 14 (26).

BORTONI-RICARDO, Stella Maris (2004). Educação em língua materna: a sociolinguística na sala de aula. São Paulo: Parábola Editorial.

DEMO, Pedro (2015). Educar pela pesquisa. 10.ed. Campinas, SP: Autores Associados.

ECKERT, Penelope (2012). "Three waves of variation study: the emergence of meaning in the study of sociolinguistic variation". Annual Review of Anthropology Palo Alto, 41, p.87-100.

FREITAG, Raquel Mester Ko; CYRANKA, Lucia Mendonça (2014). "Sociolinguística variacionista e educacional: tendências metodológicas". In: GONÇALVES, A. V.; GÓIS, M. L. DE S. (Org.) Ciências da linguagem: o fazer científico. Campinas, SP: Mercado de Letras.

HOUAISS, Antonio; VILLAR, Mauro de Salles (2009). Dicionário Houaiss de Língua Portuguesa. Elaborado pelo Instituto Antônio Houaiss de Lexicografia e Banco de Dados da Língua Portuguesa S/C Ltda. Rio de Janeiro: Objetiva.

LABOV, William (1994). Principles of linguistic change: internal factors. Oxford: Blackwell.

(1996). The social stratification of English in New York City. Washington: Center of Applied Linguistics.

(2001). Principles of linguistic change: social factors. Oxford: Blackwell. 
(2008). Sociolinguistic Patterns. Philadelphia: University of Pennsylvania Press. [Padrões Sociolinguísticos. Marcos Bagno; Marta Scherre e Caroline Cardoso (Trad.). São Paulo: Parábola].

LAMBERT, William; LAMBERT, Wallace (1968). Psicologia social. Rio de Janeiro: Zahar.

SILVA-CORVALÁN, Carmen (1989). Sociolinguística: teoría y análisis. Madrid: Alhambra.

VIEIRA, Marília Silva (2019). "Crenças e atitudes linguísticas acerca dos sequenciadores aí, daí e então na Cidade de Goiás". Guavira, 15(31).

Marília Silva Vieira é Doutora em Letras pela Universidade de São Paulo (USP) e pós-doutora em Letras (2018) pela Universidade Estadual de Mato Grosso do Sul (UEMS). Professora na Universidade Estadual de Goiás (UEG/Cora Coralina). Atua no curso de Licenciatura em Letras e no Mestrado em Língua, Literatura e Interculturalidade (POSLLI - do qual é coordenadora), com pesquisas sobre os seguintes temas: Português Brasileiro; Sociolinguística Variacionista; Crenças e atitudes linguísticas; Identidade. Autora de artigos sobre variação linguística, como: Crenças e atitudes linguísticas acerca dos sequenciadores aí, daí e então na Cidade de Goiás (Guavira Letras, 2019); Uso variável de nós e a gente em jornais publicados na Cidade de Goiás (Entrepalavras, 2019); A definição do caipira em Quirinópolis-GO: inferências para o ensino de Língua Portuguesa (Sociodialeto, 2018) e organizadora do livro Discussões e debates em língua e literatura (2018, Editora CRV). Membro do Grupo de Pesquisa e Estudos Sociolinguísticos, Dialetológicos e Discursivos da Universidade Estadual de Mato Grosso do Sul (NUPESDD - UEMS).

E-mail: vieirasmarilia@gmail.com

Rodrigo Borges Gonçalves é Mestrando em Língua, Literatura e Interculturalidade na Universidade Estadual de Goiás (UEG/Cora Coralina). Professor na Universidade Estadual de Goiás (UEG/Câmpus Sudeste).

E-mail: rborgesgonçalves@yahoo.com.br 